\title{
Optimization of Flooded Soil Recovery via Plant- Arbuscular Mycorrhizal Fungi Symbiotic Interaction
}

\author{
Nor Hazwani Aziz ${ }^{1}$, Norazwina Zainol ${ }^{1}$, Nanthinie Thangaperumal ${ }^{1}$, Nor Hanisah Zahari ${ }^{1}$ \\ ${ }^{I}$ Faculty of Chemical Engineering and Natural Resources, University Malaysia Pahang, 26300 Gambang, Pahang, \\ Malaysia. Article Info: Submitted on March 20, 2017, Accepted on June 20, 2017.
}

\begin{abstract}
Flooded soil recovery was optimized using experimental design methodology by manipulating the symbiotic relationship between soil fungi, Arbuscular Mycorrhizal Fungi (AMF) and the host plant (Allium cepa L.) planted in a soil containing AMF (SA). This was achieved by measuring the amount of nutrient (nitrogen, phosphorus and potassium) uptake by AMF using HACH spectrophotometer after 14 days of planting in several condition suggested by Design-Expert ${ }^{\circledR}$ software (Ver 7.1.6). In order to determine the optimum condition for the AMF to recover the flooded soil, the experiments were designed according to a central composite design in two variables following the Response Surface Methodology (RSM). A quadratic polynomial model was generated to predict soil recovery. R2 for nitrogen, phosphorus and potassium was found at $0.89,0.96$ and 0.94 respectively of the range for the factors studied namely $24-32 \mathrm{ml}$ water content and 4.0-6.0 cm depth of soil. Among two parameters, depth of soil showed significant effect on the recovery of flooded soil for phosphorus and potassium while for nitrogen both parameters showed insignificant effect. Model validation experiments showed good correspondence between experimental and predicted values at error for $\mathrm{N}, \mathrm{P}$, and $\mathrm{K}$ at $7.0 \%, 1.86 \%$ and $2.65 \%$ respectively. The optimal condition for soil recovery was at $28 \mathrm{ml}$ soil water content and $5 \mathrm{~cm}$ soil depth. At this condition, the nutrient uptake by AMF was predicted to be at their maximum rate where the concentration of nutrients increased approximately by 2 to 3 times from the initial nutrient concentration.
\end{abstract}

Keywords: Optimization; Flooded soil recovery; Arbuscular Mycorrhizal fungi (AMF); Onion plant; Response surface methodology.

\section{Introduction}

Malaysian weather is categorized as equatorial due to its location closed to the equator. However despite of blessed equatorial climate, Malaysia always encounter the cyclical northeast monsoon wind that eventually bring about heavy rainfall which end up by serious flood. The effect of serious flooding can be seen not only to human but also to the ecosystem, especially to land. This can be seen mainly to agricultural land since agriculture occupies a large proportion of the landscape. The floods have many direct impacts, with the most prominent one being the flooded soil syndrome where the soils losses their beneficial fungi which mobilize soil-based plant nutrients. ${ }^{1}$ Flooding and long periods of waterlogging have resulted in the depletion of nutrients. Prolonged flooding reduces the concentration of nitrogen, $\mathrm{N}$, phosphorus, $\mathrm{P}$ and potassium, K. N appears to have been denitrified and lost from the system. ${ }^{2}$ Since $\mathrm{P}$ uptake depends on microbes in most plant, prolonged waterlogging has reduced microbial activity which in turn affects the absorption of $\mathrm{P}$ into the plant roots. ${ }^{3}$ Soil $\mathrm{K}$ is less available in soils that remain wet since wet soils are more prone to compaction, which restricts plant root growth and uptake of soil K. ${ }^{4}$

Arbuscular mycorrhizal fungi (AMF) is a soil borne fungi found in almost any habitat worldwide. Symbiotic associations between AMF and plant roots are widespread in the natural environment and can provide a range of benefits to the host plant. These include improved nutrition, enhanced resistance to soil-borne pests and disease, improved resistance to drought, tolerance of heavy metals and better soil structure. ${ }^{5} \mathrm{AMF}$ enlarges the soil volume from which nutrients can be taken up, via an extensive mycelium network, enabling host plants to access more resources. ${ }^{6}$ As a consequence, AMF enhances uptake of nutrients, particularly phosphorus ${ }^{7}$, and may allow for a reduction of the amount of fertilizers applied. ${ }^{8} \mathrm{AMF}$ is an obligate symbionts, hence this fungi needs host plant in order to propagate. Onion (Allium cepa L.) has been selected as host plant for AMF to propagate considering that onion has high dependency on AMF towards water and nutrient uptake since onion has sparse rooting systems without root hairs. In addition, onion is easy to take care and their growth normally is very rapid. This research aimed to optimize the soil condition needed for AMF to recover the infertile flooded soil by manipulating plant roots-AMF symbiotic interaction. Optimization study is very crucial to improve the process of soil recovery. Identifying the optimum condition for soil recovery provides better condition for nutrient absorption by AMF. 


\section{Chemical Engineering Research Bulletin 19(2017) 67-74}

\section{Materials and Methods}

\section{Experimental Set Up}

The soil containing AMF (SA) was collected at a secondary forest zone located in Universiti Malaysia Pahang, Kuantan. Simulated flooded soil (FS) was prepared by submerging the soil in the water for two weeks. In order to determine the optimum condition for the $\mathrm{AMF}$ to recover the flooded soil, the experiments were designed according to a central composite design in two variables following the Response Surface Methodology (RSM). The experimental set up and corresponding experimental responses was presented in Table 1 . Onion bulb was planted in a pot according to the experimental design table (Table 2) in fixed condition of mixed soil (1:5 $\mathrm{SA} / \mathrm{FS}$ ) with $\mathrm{pH} 4$ and under the presence of light for fourteen days and was planted in ambient temperature.

Table 2 shows the designed factors and level to be employed for the experiment. A total of 13 experimental runs were conducted which represent 13 onion pots. The outputs of the experimental design were analyzed with Design-Expert ${ }^{\circledR}$ software (Ver 7.1.6). The response was analyzed using analysis of variance (ANOVA) based on the p-value with $95 \%$ of confidence level.

Table 1: Selected factors and corresponding range.

\begin{tabular}{|c|c|c|}
\hline \multirow{2}{*}{ Factors } & \multicolumn{2}{|c|}{ Range } \\
\cline { 2 - 3 } & Lowest & Highest \\
\hline Water content $(\mathrm{mL})$ & 24 & 32 \\
\hline Depth of soil $(\mathrm{cm})$ & 4.0 & 6.0 \\
\hline
\end{tabular}

\section{Soil Sample Analysis}

The soil was collected from each pot after 14 days for nutrient concentrations ( $\mathrm{N}, \mathrm{P}$ and $\mathrm{K}$ ) testing by using Hach Spectrophotometer. Each collected soil was sampled at the root parts, since AMF was found abundant at the roots and so are the nutrient accumulation (Tinker 1978).

\section{Validation Experiment}

The suggested optimum condition for AMF to propagate well and to recover the flooded soil was identified at $28 \mathrm{~mL}$ soil water content and with $5 \mathrm{~cm}$ soil depth. At this condition, the nutrient (N, P, and $\mathrm{K}$ ) concentration was found at their maximum value. An experiment was conducted to validate the result. Onion was planted in a pot with soil setup at $28 \mathrm{~mL}$ water content and was planted at $5 \mathrm{~cm}$ depth. The soil was sampled twice; during the first day (initial nutrient concentration) and at day 14 th in order to determine the percentage of soil recovery. The soil sample was tested for nutrient presence and the error between predicted and actual value was calculated.

Table 2: Experimental layout of face centered central composite design and its corresponding observed values of soil recovery.

\begin{tabular}{|c|c|c|c|c|c|}
\hline \multirow{2}{*}{ Run } & \multicolumn{2}{|c|}{ Variable } & \multicolumn{3}{c|}{ Response (mg/L) } \\
\cline { 2 - 6 } & $\begin{array}{c}\text { Water } \\
\text { content } \\
(\mathrm{mL})\end{array}$ & $\begin{array}{c}\text { Depth } \\
\text { of soil } \\
(\mathrm{cm})\end{array}$ & $\mathrm{N}$ & $\mathrm{P}$ & $\mathrm{K}$ \\
\hline 1 & 28 & 5.0 & 10.6 & 6.3 & 15.3 \\
\hline 2 & 24 & 5.0 & 6.4 & 4.1 & 13.2 \\
\hline 3 & 28 & 6.0 & 4.8 & 4.6 & 14.1 \\
\hline 4 & 28 & 5.0 & 10.8 & 6.2 & 15.3 \\
\hline 5 & 30 & 4.5 & 5.6 & 4.8 & 13.8 \\
\hline 6 & 28 & 5.0 & 10.6 & 6.6 & 15.3 \\
\hline 7 & 28 & 5.0 & 10.8 & 6.7 & 15.0 \\
\hline 8 & 28 & 4.0 & 5.6 & 5.4 & 13.5 \\
\hline 9 & 32 & 5.0 & 5.2 & 4.3 & 12.9 \\
\hline 10 & 28 & 5.0 & 10.8 & 6.6 & 15.0 \\
\hline 11 & 30 & 5.5 & 7.6 & 5.8 & 14.1 \\
\hline 12 & 26 & 5.5 & 6.0 & 4.7 & 14.7 \\
\hline 13 & 26 & 4.5 & 7.0 & 6.0 & 13.5 \\
\hline
\end{tabular}

\section{Results and Discussion}

\section{Fitting the model}

The experimental setup and corresponding experimental responses were shown in Table 2 . The concentration of nitrogen, $\mathrm{N}$, phosphorus, $\mathrm{P}$ and potassium, $\mathrm{K}$ shows the highest value at $28 \mathrm{~mL}$ water content and $5.0 \mathrm{~cm}$ depth of soil with the concentration of $\mathrm{N}, \mathrm{P}$ and $\mathrm{K}$ at 10.8, 6.7, and 15.3 respectively. Fitting of the data to various models (linear, two factorial, quadratic and cubic) and their subsequent analysis of variance shows that nutrient absorption by $\mathrm{AMF}$ is most properly described with a quadratic polynomial model. The adjusted R2 of the quadratic model was higher than that of linear and two factorial models for all responses. Meanwhile, the cubic model was found to be aliased. The second order polynomial model was used to express nutrient uptake by AMF (Y) as a function of independent variables.

\section{Model validation}

The adequacy of the model equations to predict optimum response values was tested using the conditions shown in Table 3. The conditions for maximum recovery of flooded soil were used to experimentally validate and predict the values of the response using the model equation. Close agreement exists between values calculated using the model 


\section{Chemical Engineering Research Bulletin 19(2017) 67-74}

equation and the experimental values of the response at the point of interest. From the established equation, the maximum nutrient absorption by AMF predicted were $10.3,6.4$ and $15.1 \mathrm{mg} / \mathrm{L}$ for $\mathrm{N}, \mathrm{P}$, and $\mathrm{K}$ respectively at parameters equal to $28 \mathrm{~mL}$ and $5 \mathrm{~cm}$ depth of soil. The actual or experimented $\mathrm{N}, \mathrm{P}$, and $\mathrm{K}$ concentration obtained were $11.0,6.3$ and $14.7 \mathrm{mg} / \mathrm{L}$ respectively. Meanwhile, percentage of error for $\mathrm{N}, \mathrm{P}$, and $\mathrm{K}$ were $7.0 \%, 1.86 \%$ and $2.65 \%$ respectively. This concludes that the error was accepted since the error percentage was not greater than $10 \%$ for all responses.

Table 3: Validation of model equation.

\begin{tabular}{|c|c|c|c|}
\hline & Expected & Predicted & Error (\%) \\
\hline $\mathrm{N}$ & 11.0 & 10.3 & 7.0 \\
\hline $\mathrm{P}$ & 6.3 & 6.4 & 1.86 \\
\hline $\mathrm{K}$ & 14.7 & 15.1 & 2.65 \\
\hline
\end{tabular}

Note: Error $(\%)=($ Experimented Predicted)/Predicted x $100 \%$.

\section{Statistical analysis for nitrogen}

\section{Analysis of variance (ANOVA)}

Table 4 summarizes ANOVA (F-test) and p-value for nitrogen that are used to estimate coefficients of the model, to check the significant of each parameter, and to indicate the interaction strength among parameter.

Table 4: ANOVA for response surface quadratic model for nitrogen.

\begin{tabular}{|c|c|c|c|c|}
\hline $\begin{array}{c}\text { Source of } \\
\text { variation }\end{array}$ & $\begin{array}{c}\text { Sum of } \\
\text { squares }\end{array}$ & $\begin{array}{c}\text { Mean } \\
\text { square }\end{array}$ & F value & $\begin{array}{c}\text { P value } \\
\text { Prob>F }\end{array}$ \\
\hline Model & 66.36 & 13.27 & 12.18 & 0.0024 \\
\hline $\begin{array}{c}\text { A-water } \\
\text { content }\end{array}$ & 0.40 & 0.40 & 0.37 & 0.5621 \\
\hline $\begin{array}{c}\text { B-depth of } \\
\text { soil }\end{array}$ & 0.030 & 0.030 & 0.028 & 0.8729 \\
\hline $\mathrm{AB}$ & 2.25 & 2.25 & 2.06 & 0.1939 \\
\hline $\mathrm{A}^{2}$ & 36.20 & 36.20 & 33.22 & 0.0007 \\
\hline $\mathrm{B}^{2}$ & 45.35 & 45.35 & 41.62 & 0.0003 \\
\hline Residual & 7.63 & 1.09 & & \\
\hline $\begin{array}{c}\text { Correlation } \\
\text { total }\end{array}$ & 73.99 & & & \\
\hline $\mathrm{R}^{2}$ & 0.8969 & & & \\
\hline${\text { Adj } \mathrm{R}^{2}}^{2}$ & 0.8233 & & & \\
\hline
\end{tabular}

It was observed from ANOVA that the confidence level was $89 \%$ while the p-value of the model was 0.0024 . The model with the p-value below than 0.05 was statistically significant, which implied that the model was suitable for this experiment. The main effects, A and B and the interaction of the main effects, $\mathrm{AB}$ was insignificant with the p-value being $0.56,0.87$ and 0.19 respectively. The coefficient of determination
$\left(\mathrm{R}^{2}\right)$ and adjusted coefficient of determination (Radj) were 0.897 and 0.823 , respectively which indicated that estimated model fits the experimental data satisfactorily. $\mathrm{R}^{2}$ should be at least 0.80 for a good fit of a model. ${ }^{9}$ The $\mathrm{R}^{2}$ for these response variables was higher than 0.80 , indicating that the regression models explained the mechanism well. Figure 1 shows the predicted versus actual soil recovery in term of nitrogen uptake by AMF. A linear distribution is observed which indicates the well-fitting model. The normal probability plot indicates that the residuals (difference between actual and predicted values) follow a normal distribution and form an approximately straight line.

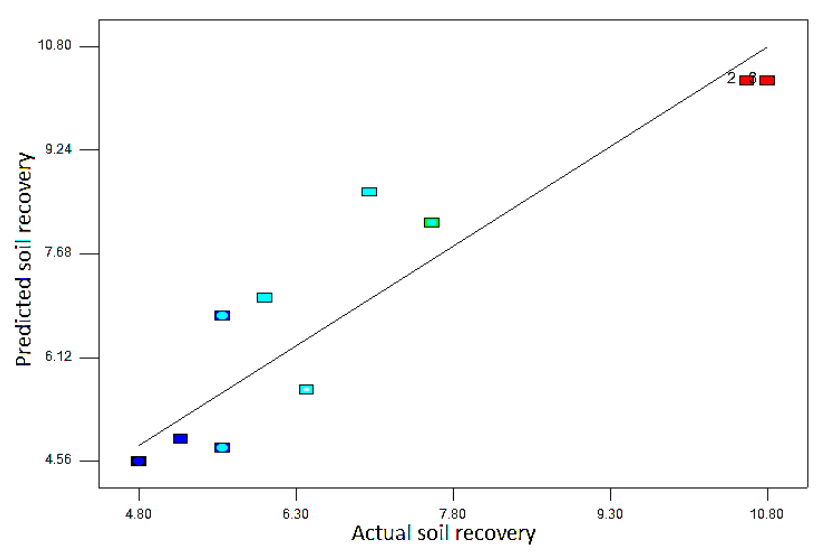

Figure 1: Correlation of actual conversions and values predicted by the model.

\section{Effect of Independent and Interactive Parameters on Nitrogen Concentration}

The effect of two independent variables on the concentration of nitrogen is shown in Figure 2. Concentration of nitrogen improved with increasing water content from $26 \mathrm{~mL}$ to $28 \mathrm{~mL}$ as shown in Figure 2a. However, upon increasing the water content from $28 \mathrm{~mL}$ to $30 \mathrm{~mL}$, nitrogen concentration is decreasing. This result indicates that excessive water content did not necessarily have a positive influence on nitrogen concentration. Meaning that $28 \mathrm{~mL}$ water content is adequate enough for AMF to uptake nitrogen from the soil. Compared to wet soil, dry soil tends to favor AMF spore germination better. ${ }^{10}$ In addition, onion requires relatively much lesser water in the soil as the onion bulb itself contain $79.8 \%$ of water compared to its dry mass. ${ }^{11}$ The effect of depth of soil on nitrogen concentration is shown in Figure $2 b$. At a soil depth of 4.5 to $5 \mathrm{~cm}$, the concentration of nitrogen shows an increasing trend. However, it decreased with the increasing soil depth from 5 to $5.5 \mathrm{~cm}$. The result simplify that at $5 \mathrm{~cm}$ soil depth, the nitrogen is abundant in the soil. About half of the microbial biomass is located in the surface of a soil profile and most of the nutrient releases by microbial activity also occurs there. ${ }^{12}$ The effect of interaction between 


\section{Chemical Engineering Research Bulletin 19(2017) 67-74}

parameters is shown in Figure 3. The figure depicts the effect of water content and depth of soil on $\mathrm{N}$ concentration. The effect of water content is more significant at $28 \mathrm{~mL}$ while the effect of depth of soil is significant at $5 \mathrm{~cm}$. At this point, the concentration of $\mathrm{N}$ is at their maximum rate absorbed by AMF.

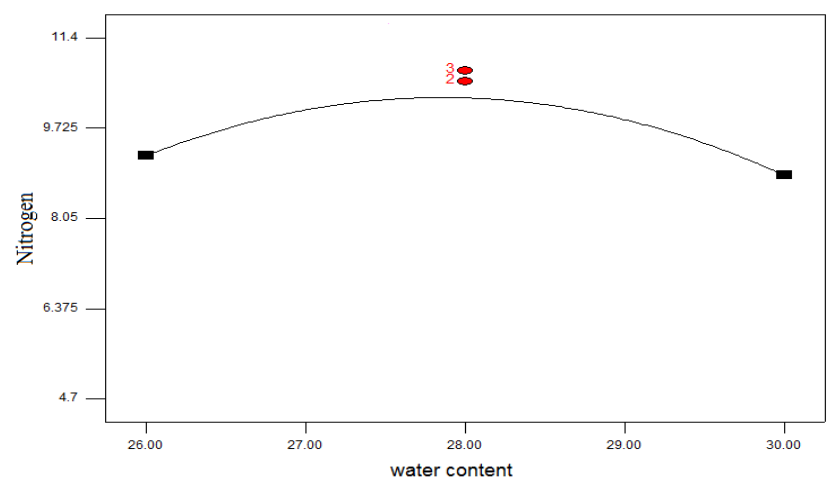

(a)

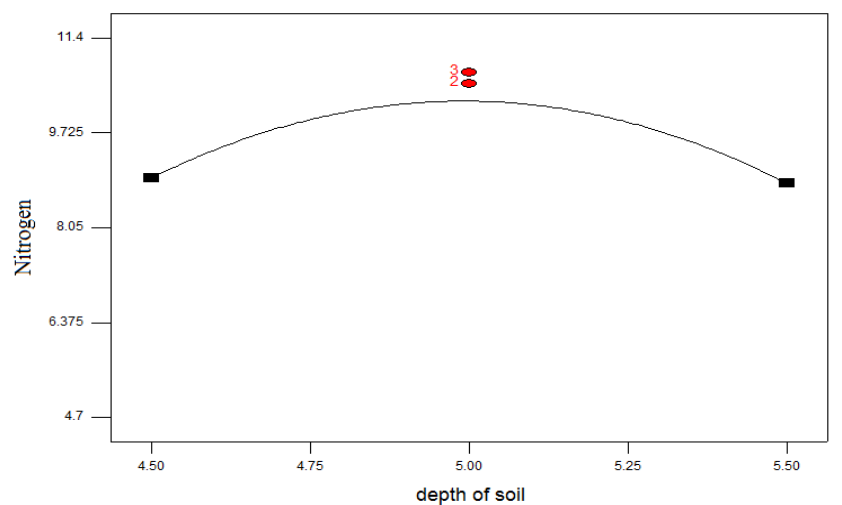

(b)

Figure 2: Effect of individual parameters: water content (a) and depth of soil (b) on the concentration of nitrogen. One parameter is varied while another one is kept constant at their center points.

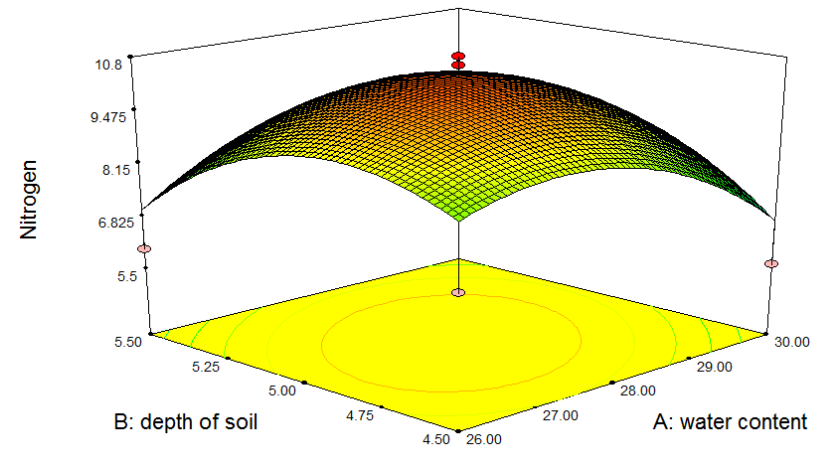

Figure 3: 3D response surface of nitrogen concentration as function of water content and depth of soil.

\section{Statistical analysis for phosphorus} Analysis of variance (ANOVA)

Table 5 summarizes ANOVA (F-test) and p-value for phosphorus. The table showed that the confidence level was greater than $95 \%$ with the p-value for model being less than 0.0001 which explained the model was statistically significant. The effect of water content on soil recovery is insignificant based on the calculated pvalue, 0.718 which was greater than 0.05 . Depth of soil and the interaction of main effects have significant effect on soil recovery which explained by the p-value of 0.049 and 0.002 respectively. The coefficient of determination $\left(R^{2}\right)$ and adjusted coefficient of determination (Radj) were 0.965 and 0.94 , respectively which indicated that estimated model fits the experimental data satisfactorily. The $\mathrm{R}^{2}$ for these response variables was higher than 0.80 , indicating that the regression models explained the mechanism well.

Figure 4 shows the predicted versus actual soil recovery in term of phosphorus uptake by AMF. A linear distribution is observed which indicatives of a well-fitting model is. The normal probability plot indicates that the residuals (difference between actual and predicted values) follow a normal distribution and form an approximately straight line.

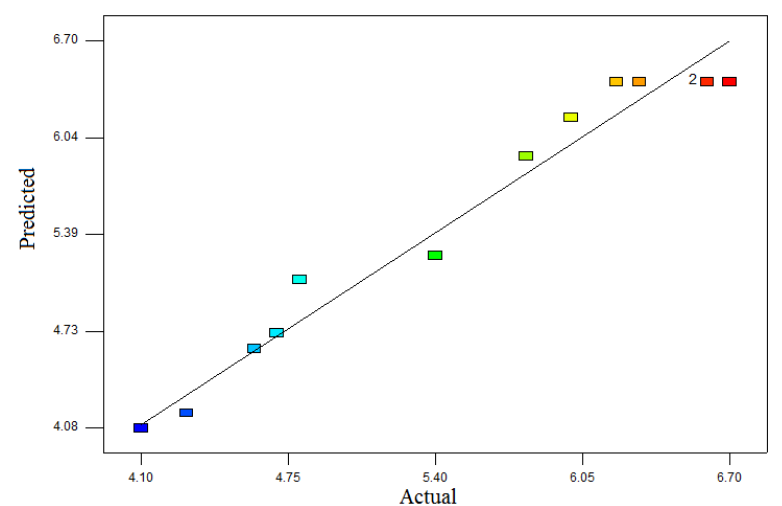

Figure 4: Correlation of actual conversions and values predicted by the model.

Table 5: ANOVA for response surface quadratic model for phosphorus.

\begin{tabular}{|c|c|c|c|c|}
\hline $\begin{array}{c}\text { Source of } \\
\text { variation }\end{array}$ & $\begin{array}{c}\text { Sum of } \\
\text { squares }\end{array}$ & $\begin{array}{c}\text { Mean } \\
\text { square }\end{array}$ & $\begin{array}{c}\mathrm{F} \\
\text { value }\end{array}$ & $\begin{array}{c}\mathrm{P} \text { value } \\
\text { Prob }>\mathrm{F}\end{array}$ \\
\hline Model & 10.28 & 2.06 & 38.67 & $<0.0001$ \\
\hline $\begin{array}{c}\text { A-water } \\
\text { content }\end{array}$ & $\begin{array}{c}7.500 \mathrm{E}- \\
003\end{array}$ & $\begin{array}{c}7.500 \mathrm{E}- \\
003\end{array}$ & 0.14 & 0.7184 \\
\hline $\begin{array}{c}\text { B-depth of } \\
\text { soil }\end{array}$ & 0.30 & 0.030 & 5.66 & 0.0490 \\
\hline $\mathrm{AB}$ & 1.32 & 1.32 & 24.87 & 0.0016 \\
\hline $\mathrm{A}^{2}$ & 7.54 & 7.54 & 141.84 & $<0.0001$ \\
\hline $\mathrm{B}^{2}$ & 3.20 & 3.20 & 60.19 & 0.0001 \\
\hline Residual & 0.37 & 0.053 & & \\
\hline $\begin{array}{c}\text { Correlation } \\
\text { total }\end{array}$ & 10.65 & & & \\
\hline $\mathrm{R}^{2}$ & 0.9651 & & & \\
\hline Adj R $^{2}$ & 0.9401 & & & \\
\hline
\end{tabular}




\section{Chemical Engineering Research Bulletin 19(2017) 67-74}

Effect of Independent and Interactive Parameters on Phosphorus Concentration

The effect of two independent variables on the concentration of phosphorus is shown in Figure 5. Concentration of phosphorus is increasing with the increasing water content from $26 \mathrm{~mL}$ to $28 \mathrm{~mL}$ as shown in Figure 5a. However, the concentration of phosphorus is decreasing upon the increasing water content from $28 \mathrm{~mL}$ to $30 \mathrm{~mL}$. This shows that excessive water content did not necessarily have a positive effect on phosphorus concentration. Meaning that $28 \mathrm{~mL}$ water content is adequate enough for AMF to uptake phosphorus from the soil. The effect of depth of soil on phosphorus concentration is shown in Figure $5 \mathrm{~b}$. At a soil depth of 4.5 to $5 \mathrm{~cm}$, the concentration of phosphorus shows an increasing trend. However, it decreased with the increasing soil depth from 5 to 5.5 $\mathrm{cm}$. The result indicates that phosphorus concentration is high at $5 \mathrm{~cm}$ depth of soil. The losses of phosphorus occur from approximately at the top $5 \mathrm{~cm}$ of soil ${ }^{13,14}$. The accumulation of phosphorus normally occurs in the topsoil because it cannot be found in gaseous phase under natural condition ${ }^{15}$.

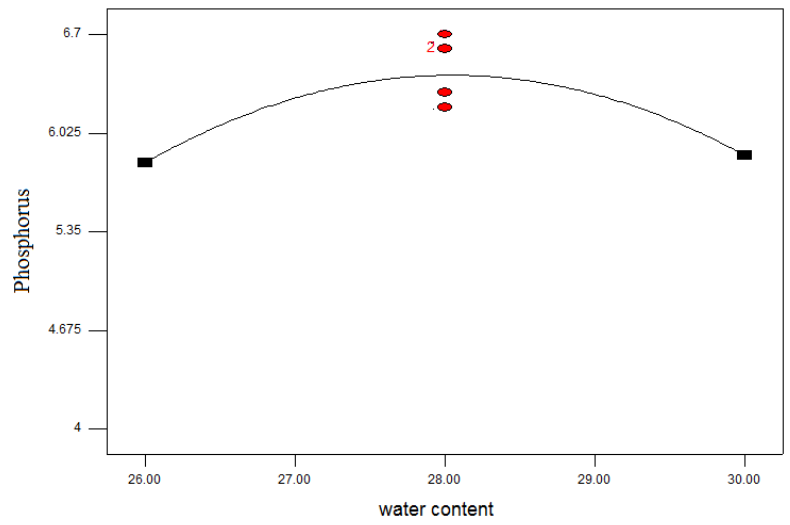

(a)

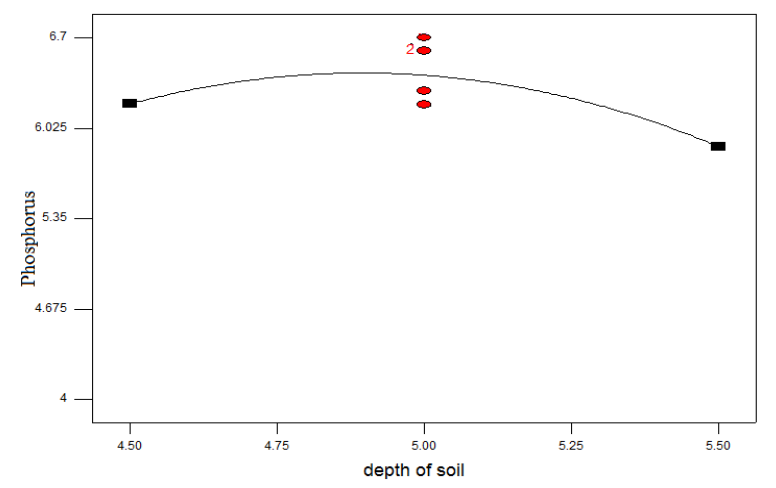

(b)

Figure 5: Effect of individual parameters: water content (a) and depth of soil (b) on the concentration of phosphorus. One parameter is varied while another one is kept constant at their center points.

Figure 6 shows the effect of interaction between parameters. The figure shows the effect of water content and depth of soil on P concentration. The effect of water content is more significant at $28 \mathrm{~mL}$ while the effect of depth of soil is significant at $5 \mathrm{~cm}$. At this point, the concentration of $\mathrm{P}$ is at their maximum rate absorbed by AMF.

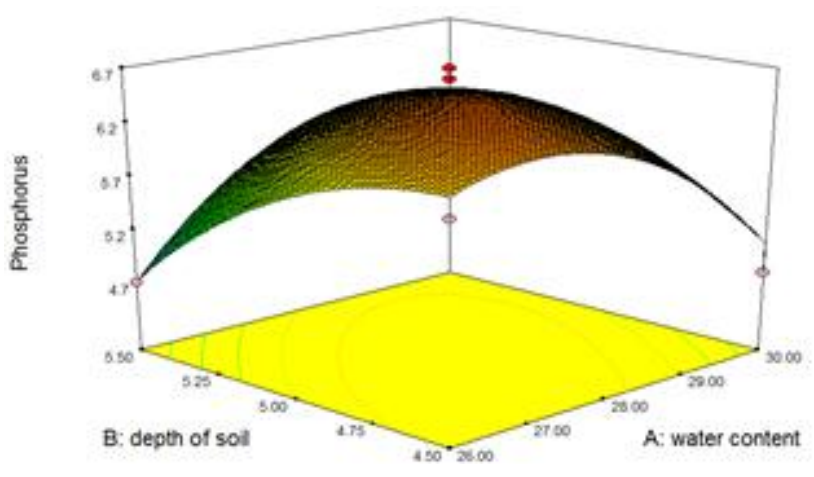

Figure 6: 3D response surface of phosphorus concentration as function of water content and depth of soil.

\section{Statistical analysis for potassium}

Analysis of variance (ANOVA)

Table 6 summarizes ANOVA (F-test) and p-value for potassium.

Table 6: ANOVA for response surface quadratic model for potassium.

\begin{tabular}{|c|c|c|c|c|}
\hline $\begin{array}{c}\text { Source of } \\
\text { variation }\end{array}$ & $\begin{array}{c}\text { Sum of } \\
\text { squares }\end{array}$ & $\begin{array}{c}\text { Mean } \\
\text { square }\end{array}$ & F value & $\begin{array}{c}\text { P value } \\
\text { Prob }>F\end{array}$ \\
\hline Model & 8.46 & 1.69 & 26.01 & 0.0002 \\
\hline $\begin{array}{c}\text { A-water } \\
\text { content }\end{array}$ & 0.068 & 0.068 & 1.04 & 0.3423 \\
\hline $\begin{array}{c}\text { B-depth of } \\
\text { soil }\end{array}$ & 0.61 & 0.61 & 9.34 & 0.0184 \\
\hline $\mathrm{AB}$ & 0.20 & 0.20 & 3.11 & 0.1211 \\
\hline $\mathrm{A}^{2}$ & 6.61 & 6.61 & 101.67 & $<0.0001$ \\
\hline $\mathrm{B}^{2}$ & 2.80 & 2.80 & 43.09 & 0.0003 \\
\hline Residual & 0.46 & 0.065 & & \\
\hline $\begin{array}{c}\text { Correlation } \\
\text { total }\end{array}$ & 8.92 & & & \\
\hline $\mathrm{R}^{2}$ & 0.9489 & & & \\
\hline Adj R $^{2}$ & 0.9124 & & & \\
\hline
\end{tabular}

The table showed that the confidence level was greater than $90 \%$ with the p-value of the model being 0.0002 which explained the model was statistically significant. The effect of water content and the interaction between main effects on soil recovery exhibited a p-value of 0.342 and 0.121 . This exceeds a p-value level of 0.05 and indicates that the effects is not significant. Depth of soil showed significant effect on soil recovery in term of potassium uptake by AMF. This described by the p-value, 0.018 which was lower than 0.05 . The coefficient of determination $\left(\mathrm{R}^{2}\right)$ and adjusted 


\section{Chemical Engineering Research Bulletin 19(2017) 67-74}

coefficient of determination (Radj) were 0.949 and 0.912 , respectively which indicated that estimated model fits the experimental data satisfactorily. The $\mathrm{R}^{2}$ for these response variables was higher than 0.80 , indicating that the regression models explained the mechanism well. Figure 7 shows the predicted versus actual soil recovery in term of potassium uptake by AMF. A linear distribution is observed which indicatives of a well-fitting model is. The normal probability plot indicates that the residuals (difference between actual and predicted values) follow a normal distribution and form an approximately straight line.

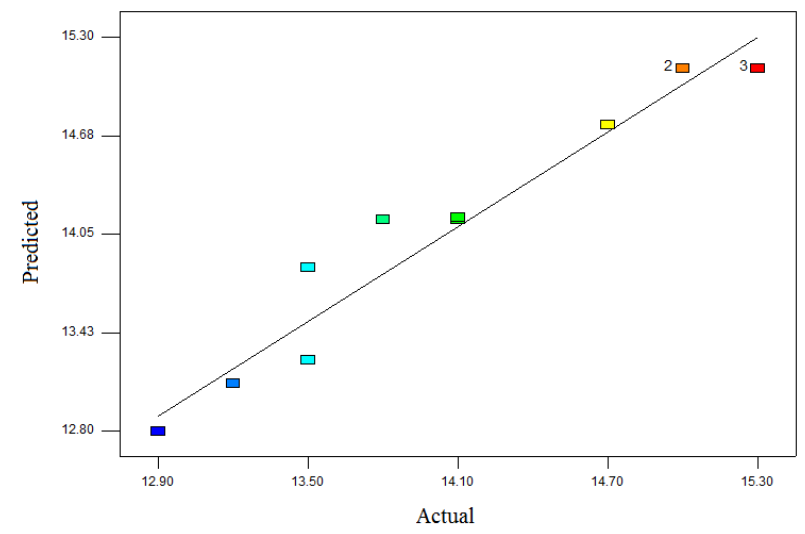

Figure 7: Correlation of actual conversions and values predicted by the model.

\section{Effect of Independent and Interactive Parameters on Potassium concentration}

The effect of two independent variables on the concentration of potassium is shown in Figure 8. Potassium concentration improved with increasing water content from $26 \mathrm{~mL}$ to $28 \mathrm{~mL}$ as shown in Figure $8 \mathrm{a}$ but decrease at water content from $28 \mathrm{~mL}$ to $30 \mathrm{~mL}$. This implies that excessive water content did not necessarily have a positive consequence on potassium concentration. Meaning that $28 \mathrm{~mL}$ water content is adequate enough for AMF to uptake potassium from the soil. Onion requires less water in the soil because the onion bulb contain $79.8 \%$ of water compared to its dry mass ${ }^{16}$. The effect of depth of soil on potassium concentration is shown in Figure 8b. At a soil depth of 4.5 to $5 \mathrm{~cm}$, the concentration of potassium is increasing but decreased with the increasing soil depth from 5 to $5.5 \mathrm{~cm}$. The result indicates that potassium concentration is high at $5 \mathrm{~cm}$ soil depth. Potassium levels can be found highest at the surface of the soil. ${ }^{14}$ Even though potassium can be found abundant in the soil, most of the potassium forms is not available for plants to be used. Plants can only use the exchangeable potassium on the surface of soil particles and potassium dissolved in the soil water.

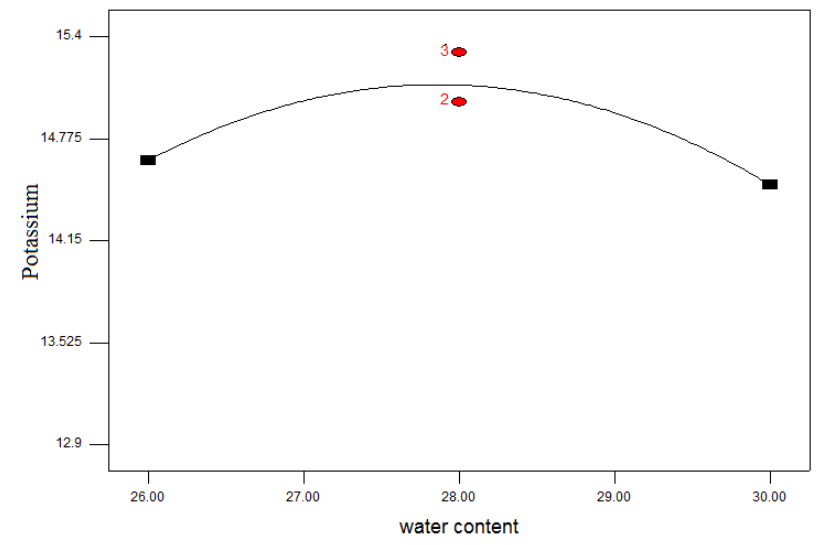

(a)

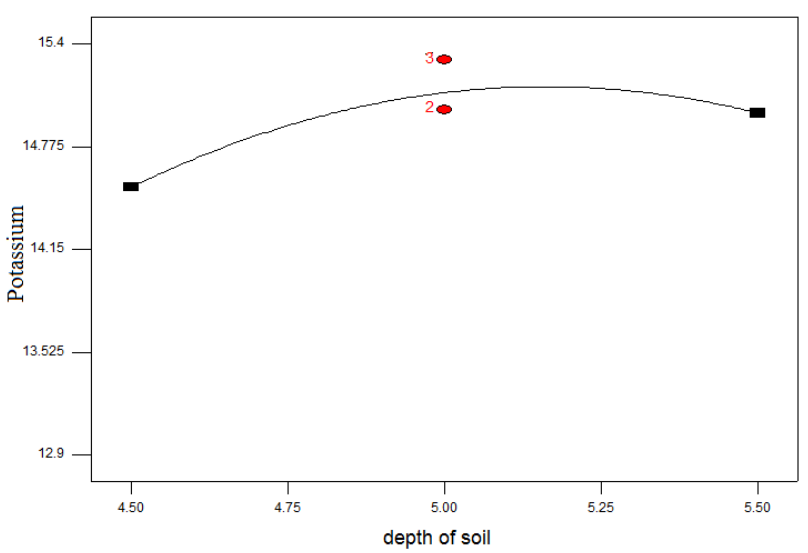

(b)

Figure 5: Effect of individual parameters: water content (a) and depth of soil (b) on the concentration of potassium. One parameter is varied while another one is kept constant at their center points.

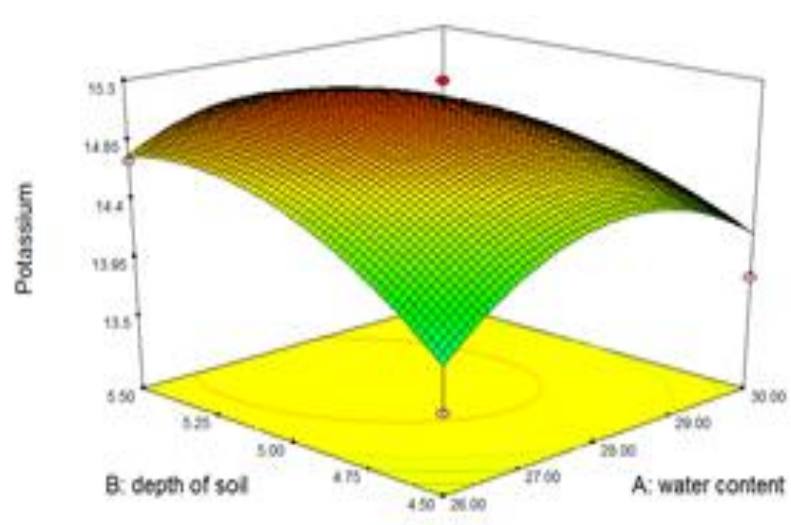

Figure 9: 3D response surface of potassium concentration as function of water content and depth of soil.

The effect of interaction between parameters is shown in Figure 9. The figure represents the effect of water content and depth of soil on $\mathrm{K}$ concentration. The effect of water content is more significant at $28 \mathrm{~mL}$ 


\section{Chemical Engineering Research Bulletin 19(2017) 67-74}

while the effect of depth of soil is significant at $5 \mathrm{~cm}$. At this point, the concentration of $\mathrm{K}$ is at their maximum rate absorbed by AMF.

\section{Conclusion}

A central composite RSM design was used to determine the optimum conditions for the soil recovery in terms of nutrient uptake by AMF. It is found that water content, depth of soil and the quadratics of water content and soil depth, as well as interaction between water content and depth of soil are significant factors affecting the soil recovery. P-value from ANOVA test shows that water content and depth of soil have significant effect on the recovery for phosphorus and potassium concentration. Conversely, both parameters shows insignificant effect on nitrogen concentration. The second order polynomial equation developed in this study shows a high correlation between experimented and predicted nutrient concentration values. Response surface analysis was found to be a good approach for visualizing process-parameter interaction. The models developed by RSM shall be useful for predicting the optimum processing condition to achieve maximum nutrient concentration. Nutrient (N, P and $\mathrm{K}$ ) absorption by AMF at water content and soil depth equals to $28 \mathrm{~mL}$ and $5 \mathrm{~cm}$ respectively gave an actual of $\mathrm{N}, \mathrm{P}$ and $\mathrm{K}$ concentration of $11,6.3$ and $14.7 \mathrm{mg} / \mathrm{L}$ respectively which closely matches the predicted values of 10.3, 6.4 and $15.1 \mathrm{mg} / \mathrm{L}$ of $\mathrm{N}, \mathrm{P}$ and $\mathrm{K}$ respectively. This values shows an approximately 2 to 3 times increasing in the concentration from the initial tested concentration of N, P and K. Flooded soil recovery is represented by the amount of nutrient concentration absorbed by AMF.

\section{Acknowledgement}

This study was financially supported by the Research Grant RDU140121 from Kementerian Pendidikan Malaysia. The authors are grateful to all from the Faculty of Chemical Engineering and Natural Resources, University Malaysia Pahang for contribution in all technical and analytical support as well as valuable suggestions.

\section{References}

1. J. Sawyer, A. P. Mallarino and M. Al-Kaisi, "Flooded Soil Syndrome Fact Sheet," Iowa State Univ. Ext. and Univ. Nebraska-Lincoln Extension, Ames, IA and Lincoln, NE, 2011.
2. J. Kreuzwieser, S. Fürniss and H. Rennenberg, "Impact of waterlogging on the N-metabolism of flood tolerant and non-tolerant tree species," Plant, Cell \& Environment, vol. 25, pp. 1039-1049, 2002.

3. J. R. Ellis, "Post Flood Syndrome and VesicularArbuscular Mycorrhizal Fungi," Journal of Production Agriculture, vol. 11, pp. 200-204, 1998.

4. J. Lipiec and W. Stepniewski, "Effects of soil compaction and tillage systems on uptake and losses of nutrients," Soil Tillage Research, vol. 35, pp. 37-52, 1995.

5. P. Gosling, A. Hodge, G. Goodlass and G. D. Bending, "Arbuscular mycorrhizal fungi and organic farming," Agriculture, Ecosystems \& Environment, vol. 113, no. 1-4, pp. 17-35, 2006.

6. R. D. Finlay. "Mycorrhizal fungi and their multifunctional roles," Mycologist, vol. 18, pp. 91-96, 2004.

7. C. Plassard and B. Dell, "Phosphorus nutrition of mycorrhizal trees," Tree Physiology, vol. 30, pp. 1129-1139, 2010.

8. 8.R. Abdullahi and H. H. Sheriff, "Effect of arbuscular mycorrhizal fungi and chemical fertilizer on growth and shoot nutrients content of onion under field condition in northern Sudan Savanna of Nigeria," IOSR Journal of Agriculture and Veterinary Science, vol. 3, no. 5, pp. 85-90, 2013.

9. A. Lee, N. Chaibakhsh, M. B. A. Rahman, M. Basri and B. A. Tejo, "Optimized enzymatic synthesis of levulinate ester in solvent-free system," Industrial Crops and Products, vol. 32, pp. 246-251, 2010.

10. J.M. Wilson, "Comparative development of infection by three vesicular-arbuscular mycorrhizal fungi," New Phytologist, vol. 97, pp. 413-426, 1984.

11. D. Davies, "Alliums. The Ornamental Onions. Covers about 200 species of Alliums. A very short section on their uses, good details of their cultivation needs", 1992.

12. D.V. Murphy, G.P. Sparling and I.R.P. Fillery, "Stratification of microbial biomass $\mathrm{C}$ and $\mathrm{N}$ and gross $\mathrm{N}$ mineralization with soil depth in two contrasting Western Australian Agricultural soils, "Australian Journal of Soil Research, vol. 36, pp. 45-55, 1998.

13. S. M.Faulkner, C. W.Wood, D. W.Reeves, R. L. Raper and G. E. Brink, "Use of Tillage to Redistribute Phosphorus in Nutrient Overloaded Soils". American Society of Agronomy, Crop Science Society of America, Soil Science Society of America, 1999.

14. H. A. Torbert, T. C. Daniel, J. L. Lemunyon and R. M. Jones, "Relationship of soil test phosphorus 


\section{Chemical Engineering Research Bulletin 19(2017) 67-74}

and sampling depth to runoff phosphorus in calcareous and noncalcareous soils,"Journal of Environmental Quality, vol. 31, pp. 1380-1387, 2002.

15. J. C. Franchini, M. A.Pavan and M. Miyazawa, "Redistribution of phosphorus in soil through cover crop roots, "Brazilian Archives of Biology and Technology, vol. 47, no.3, pp. 381-386, 2004.
16. N. K. Edwards, "Distribution of potassium in the soil profile of a sandplain soil under pasture species, "Plant and Soil, vol. 155-156, no. 1, pp. 407, 1993.

17. E. E.Schulte and K. A. Kelling, "Soil and applied potassium". Understanding Plants Nutrients. Cooperative Extension Publications, University of Wisconsin-Extension, 1992.

\section{Available online at http://www.banglajol.info/index.php/CERB}

